\title{
Development of the Metanephric Anlage of Chick in Allantoic Grafts
}

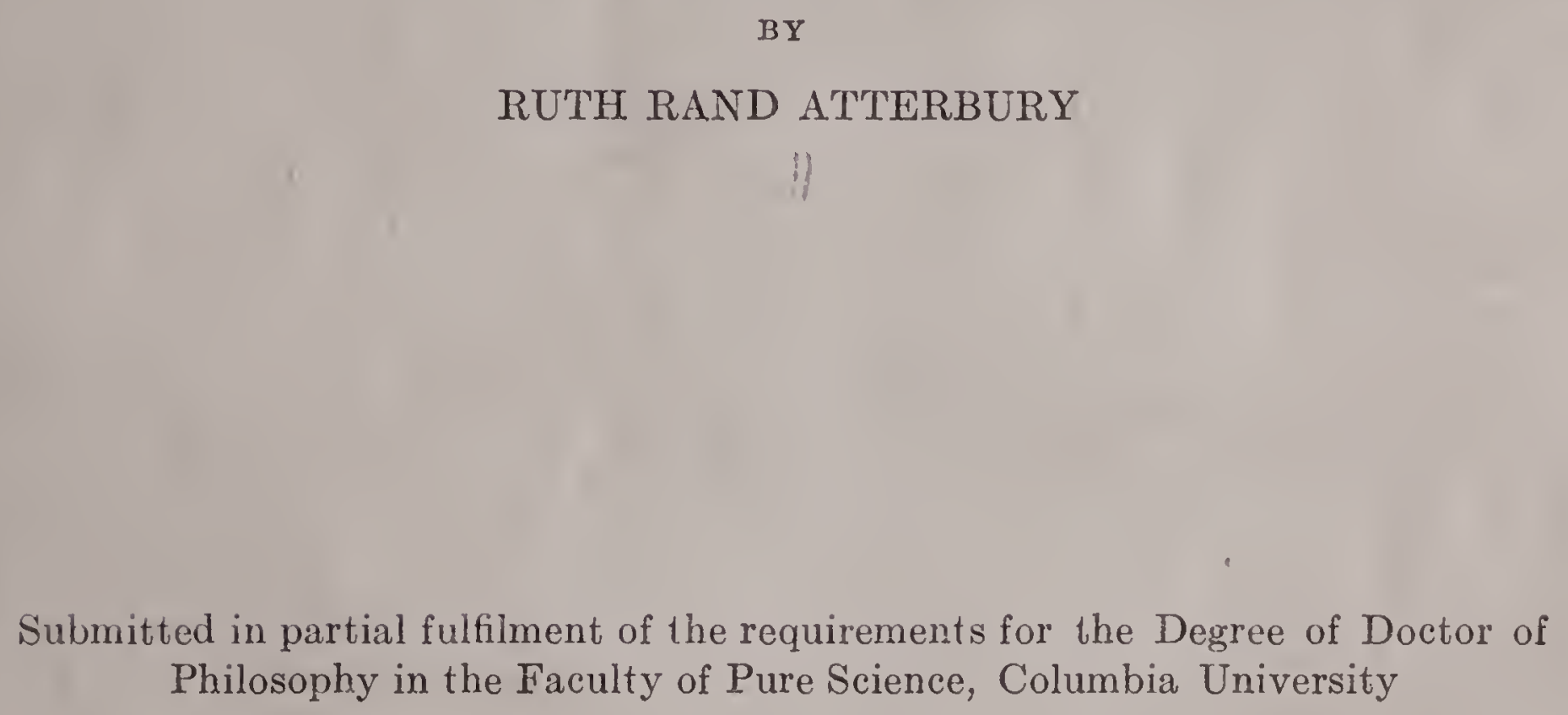
Philosophy in the Faculty of Pure Science, Columbia University

NEW YORK

1923

Reprinted from The American Journal of Anatomy, Volume 31, Number 4, March, 1923 



\title{
DEVELOPMENT OF THE METANEPHRIC ANLAGE OF CHICK IN ALLANTOIC GRAFTS
}

\author{
RUTH RAND ATTERBURY \\ Department of Anatomy, Columbia University \\ FIVE TEXT FigdRES AND THREe Plates (SEVEN FigURES)
}

CONTENTS

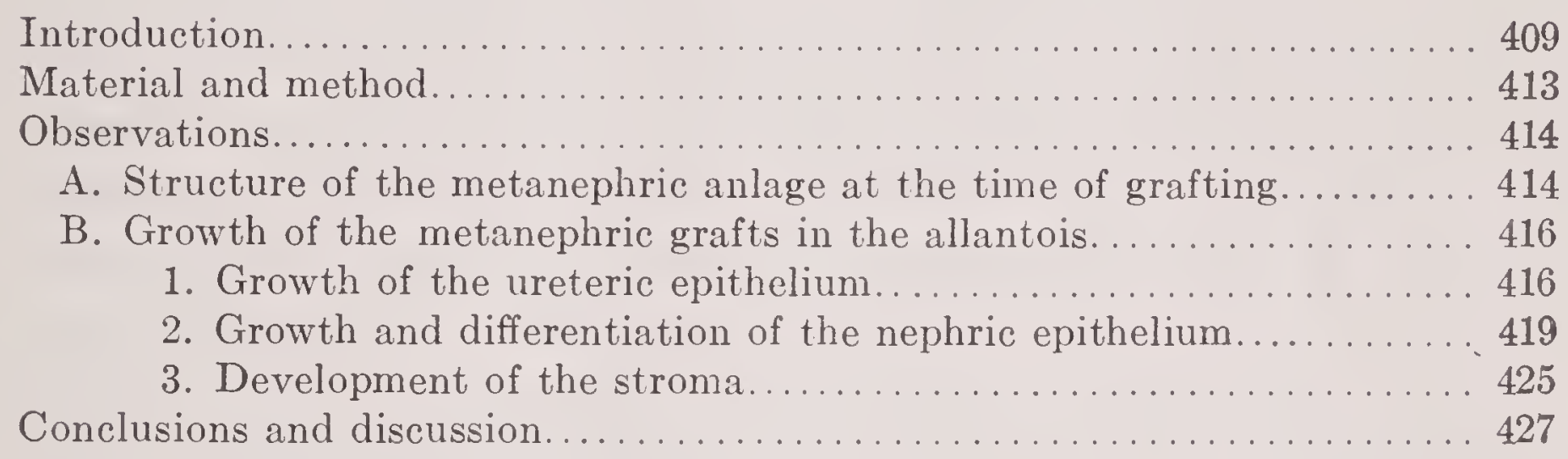

\section{INTRODUCTION}

The kidney is a structure peculiarly adapted for a study of the much-discussed problems of cell potentialities and cell differentiation and frequently has been used by investigators for this purpose. As is known the anlage of the permanent kidney is twofold consisting of, 1) the ureter bud, which gives rise to the collecting apparatus of the definitive kidney, and, 2) the metanephrogenic cord, a strand of apparently uniform mesenchymal tissue into which the ureter bud grows.

The cells of the metanephrogenic cord are mesodermic in origin. They arise from the primitive segment stalks of the two or three most caudal somites, which lose their metameric arrangement, fusing together into a continuous nephrogenic strand or cord. In the course of its development, the metanephrogenic cord takes two distinct lines of differentiation. On the one hand it is transformed into the highly differentiated secretory epithelium of the renal tubules, while on the other hand it gives rise to the connective-tissue capsule and stroma of the kidney. 
Thus two zones are usually distinguished in the metanephrogenic strand, an inner and an outer zone. The secretory cells of the nephric tubules are believed to arise from the inner zone, the stroma cells, from the outer zone. The cells of both zones are mesenchymal in character, and in the early stages of development essentially similar in structure. A difference in density of the tissue seems to be the only morphological distinction between these zones.

The mesenchyme-like tissue of the kidney anlage, abundant in early stages of development, diminishes gradually in amount with the specific differentiation of the nephric tubules. In later stages of development, as well as in the adult kidney, the stroma consists of sparse, apparently inert, connective-tissue cells scattered among the renal tubules and about the blood vessels. Under pathological conditions this tissue in man may proliferate intensively (nephritis interstitialis). The appearance of bone, bone-marrow, and blood formation following special experimental conditions has been described in the kidney of the adult rabbit by Sacerdotti and Frattin ('02), by Poscharissky ('05), and Maximov ('07). The formation of bone and bonemarrow was interpreted by these authors as a local metaplasia of the connective-tissue cells of the stroma. According to Maximov, however, the blood formation observed in these experiments is to be interpreted as a local proliferation of young blood cells brought into the kidney from other hemopoietic centers by way of the blood current. In the opinion of Maximov, no one can seriously entertain a belief in the possibility of hemopoietic potency in the scanty connective tissue of the adult kidney.

Only in lower forms is the kidney regularly a seat of hemopoiesis - the mesonephros of fishes being a permanent organ of blood formation. The meso- and metanephros of birds and mammals never display hemopoietic activity either in embryonic development or in the normal adult condition. However, it was shown by Danchakoff that in chick embryos the stroma of both the meso- and metanephros possesses hemopoietic potency, although under normal conditions this is not revealed. A marked 
granuloblastic transformation of the loose embryonic mesenchyme in chick embryos was experimentally produced, the stroma of the meso- and metanephros being included in the general reaction. The development and differentiation of the nephric tubules in these embryos proceeded, however, in the usual way without any apparent disturbance. New nephric tubules continued to form, but were separated by strands of granuloblastic tissue. In the metanephros the granuloblastic metaplasia was less marked than in the mesonephros. Contrary to what was observed in the mesonephros, comparatively few mobile cells developed from the apparently uniform mesenchyme of the metanephrogenic cord. The question as to whether the nephrogenic tissue consists of two substantially different tissues (anlages of renal epithelium and stroma) appearing under the aspect of morphologically identical cells, was left undecided by Danchakoff:

It is true, that the factors for the granuloblastic differentiation of the mesenchymal stroma become, under the present experimental conditions, so powerful as to transform a large amount of mesenchymal cells into granuloblasts even in a region of the organism in which granulopoiesis has never occurred in a typical development. It would, therefore, be only natural to expect that, if the nephrogenic tissue proper possessed a potentiality for granuloblastic differentiation, it would have manifested it under the present condition. The granuloblastic potentiality may, however, still be a property of the nephrogenic tissue, but the factor's for the specific organization of the nephrogenic tissue into the renal epithelial tubules, which are unknown to us, may be of a more decisive nature for their realization.

More information concerning the development and differentiation of the nephrogenic anlage may be obtained by a study of the development of the anlage isolated from its normal environment and allowed to grow outside of the organism. Champy studied in detail the behavior of adult and embryonic kidney tissue outside the organism. Using Harrison's tissue culture method as modified by Burrows and Carrel, he observed first an intensive proliferation of the cells of the renal tubules, followed by disintegration of the tubules to form cords of epithelial cells. According to his observations, the cords of epithelial 
cells later broke down, their cells intermingling with those of the connective tissue to form an undifferentiated mesenchymal tissue. His conclusions are somewhat surprising. A fully differentiated kidney epithelium exercising in the organism a highly specialized function, if transplanted into an artificial cultuie medium, not only continues to live, but shows itself capable of a series of reversible reactions which bring it back to its undifferentiated state.

Uninterrupted growth of tissue for a considerable length of time is not conveniently obtained by the tissue-culture method. New data concerning the developmental potencies of the nephrogenic tissue might be secured if the nephrogenic anlage were isolated from its normal relations within the organism and transplanted into a milieu which would permit of its undisturbed growth throughout a considerable period of time. At the suggestion of Doctor Danchakoff, I undertook the problem of studying the course of development of the metanephric anlage transplanted into the allantois of the chick embryo. The metanephric anlage of a chick of seven days' incubation was chosen because, 1) at this stage the process of differentiation, though started, has not proceeded very far (for example, the Malpighian corpuscles are entirely lacking), and, 2) at this stage it is relatively easy to separate the metanephric anlage from the surrounding olgans.

In this study special attention has been given to the gradual differentiation of the specific structures of the kidney from the morphologically homogeneous mesenchyme, which at the time of grafting forms the greatest part of the metanephric anlage. The development of the stroma has also been studied in detail especially with reference to its hemopoietic potency.

I wish to express my gratitude to Doctor Danchakoff, to whom I owe the problem, for her constant help and kind encouragement in this work. 


\section{MATERIAL AND METHOD}

The material upon which this investigation is based consists for the most part of grafts of the metanephric anlage isolated from chick embryos at a stage of seven days' incubation and grown on the allantois of seven-day chick embryos. The eggs were opened under aseptic conditions and the embryos laid out in sterilized glass dishes. An opening was made along the ventral midline, and the heart, liver, and digestive tract were cut away. The glands and ducts of the urogenital system were thus exposed. Before attempting to isolate the metanephric anlage, it was found most convenient to remove the whole urogenital system from the body cavity and to transfer it to a watchglass, disturbing the general relations as little as possible. Thus the metanephric anlage in relation to the various parts of the urogenital system could more readily be seen and dissected out. The metanephric anlage was separated out by cutting the ureteric diverticulum just above its entrance into the cloaca and by teasing the anlage apart from its connections with other tissues. The organ at this stage is about $1 \mathrm{~mm}$. in length. Care was taken to keep the tissues well moistened with blood plasma during the process of isolation. Text figure $\mathrm{A}$ is a diagram of the separated metanephros as it appeared under the binocular microscope. The figure shows that the metanephric diverticulum has already begun to branch. The branches are arranged in two groups, a cranial, larger group, and a caudal, smaller group, joined together by an unbranched portion of the ureteric channel.

The eggs used as hosts for the grafts were likewise at a stage of seven days' incubation. At this time the allantois is well supplied with a vascular net and conditions are extremely favorable for the establishment of vascular connections between the graft and the host. The method of procedure in the grafting was that used and described by Danchakoff ('16). A window was sawed out over a large allantoic vessel, upon which the metanephric anlage was carefully laid. In some cases the entire metanephric anlage was grafted, in other cases only its 
cranial or its caudal part. The window was closed and sealed with paraffin and the egg returned to the incubator. The grafts were permitted to grow through various stages ranging from one to twelve days. Helly's fluid was used for fixation and celloidin for embedding. The blocks were cut in serial sections and stained in eosin-azur.

\section{OBSERVATIONS}

A. Structure of the metanephric anlage at the time of grafting

In order to determine the extent of growth and differentiation of the metanephric anlage in the allantois, a careful study was made of the structure which the anlage presented at the time of grafting. As seen in text figure $\mathrm{A}$, the ureteric bud at this stage has already grown into the tissue of the metanephrogenic strand and has given rise to two groups of short branches, a cranial group and a caudal group. These branches constitute the primordia of the collecting tubules of the kidney. The ureteric branches of the caudal group are apparently in a slightly more advanced stage of development than the cranial. They seem somewhat longer and in several instances they have begun to give off secondary branches. Figure 1 is a photograph from a section of the metanephric anlage of a seven-day chick embryo and illustrates the extent of differentiation at this stage. The figure represents a section from the caudal, and, therefore, the most highly differentiated, part of the anlage. The ureter, cut longitudinally, appears in the form of a tubule with a distinct lumen. This tubule has given off a primary ureteric branch which has started a further dichotomous division, forming in this way secondary branches. The lumen of both the ureter and its derivative is lined with simple columnar epithelium. The nuclei of the epithelial cells are large and have distinct nucleoli. Mitotic figures at this stage are found in large numbers.

Text figure A shows the branches of the metanephric diverticulum thickly covered with dense masses of cells. In sections these appear in the form of a mantle of mesenchymal cells in close apposition with the branches of the ureter bud. These cells 
constitute the nephrogenous tissue proper. The cells in immediate contact with the ureteric epithelium appear somewhat hypertrophied. They have acquired an epithelial arrangement, grouping themselves radially around the ureteric epithelium. The cells at a distance from the ureteric branches are smaller and less densely packed.

The accounts of the normal development of the metanephros usually describe the nephrogenous tissue as being divided into two zones-an inner zone, the anlage of the secretory tubules

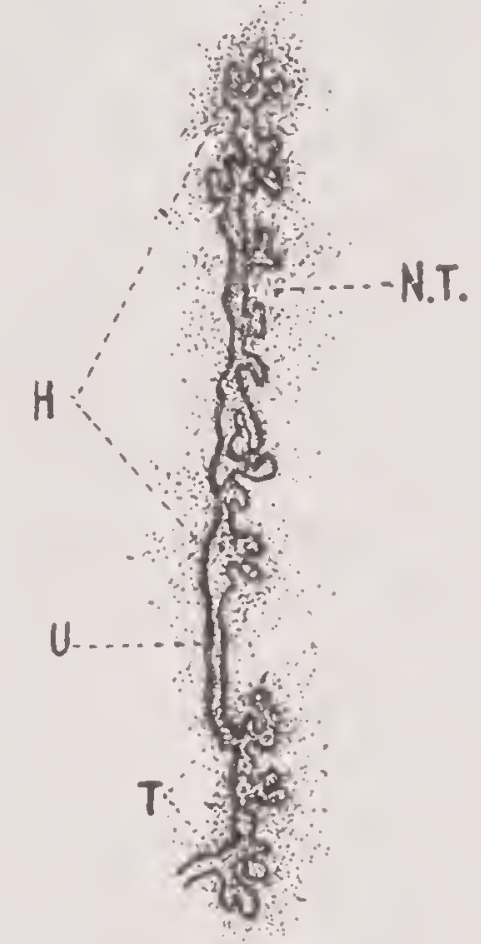

Text figure A Diagrammatic drawing of metanephric analage, isolated from a seven-day chick embryo, as it appeared under dissecting microscope. $H$, cranial group of ureteric branches; $N$.T., nephrogenous tissue; $T$, caudal group of ureteric branches; $U$, unbranched portion of ureteric channel.

proper, and an outer zone, the anlage of the connective-tissue capsule and stroma of the kidney. The outer zone is described as developing in advance of the inner zone and forming a rather broad investment around the organ. According to Felix, the two zones are particularly well defined in the sea-gull. But both Felix and Lillie agree that in the chick it is practically impossible to distinguish the two zones. As seen from figure 1, the two zones are indistinguishable in the anlage of the seven-day chick embryo. The denser tissue around the ureteric branches merges 
gradually into the looser mesenchyme which invests the whole anlage and which also occupies all the interstices between the ureteric branches.

\section{B. Growth of the metanephric grafts in the allantois}

It may be stated at once that both the ureter bud and the nephrogenous tissue proper survive and grow when grafted on the allantois. Indeed, the metanephric anlage of a seven-day chick embryo seems as fully capable of growth and differentiation in the allantois as in its normal environment within the organism. Figures 2 and 7 represent the metanephric anlage after seven and ten days' growth, respectively, and illustrate to what extent growth and differentiation may proceed. Figure 2 is remarkable in showing that the metanephric anlage has developed in the form of two separate lobes, a larger and a smaller one. These two lobes, joined together by the main ureteric channel, have developed evidently from the cranial and caudal groups of ureteric branches present in the anlage at the time of grafting (text figure A). Figure 7 represents a section through a metanephros, the development and differentiation of which took place in the allantois. Almost all of this tissue has developed during the ten days' growth in the allantois. The tiny metanephric anlage, which at the time of grafting was scarcely the size of a pinhead, has been transformed into a large, highly complex, lobulated organ very similar to the normal kidney of a chick embryo of corresponding age (seventeen days).

The process of growth and differentiation of the metanephric anlage in the allantois was carefully studied and compared with the development of an undisturbed anlage at corresponding stages. For sake of clearness these observations will be recorded under separate headings: 1) Growth of the ureteric epithelium; 2) Growth and differentiation of the nephric epithelium; 3) Development of the stroma.

1. Growth of the ureteric epithelium. The early stages of development of the metanephric structures in the allantois can be more easily followed by the study of the growth of the cranial 
part of the anlage, which, at the time of grafting, is slightly less advanced in the process of differentiation. Just as in typical development, the primary ureteric branches grow in the allantois and carry with them parts of the nephrogenous tissue which closely cap their somewhat expanded ends. Aftel the branches have attained a certain length, dichotomous division takes place at their blind terminations, giving rise to secondary tubules. This usually occurs at the end of the first or in the early part of the second day of growth in the allantois. Figure 3 represents a section through a graft of the metanephric anlage after twentyfour hour's' growth in the allantois and illustrates well the branching of a primary ureteric tubule and the development of the secondary tubules. The primary tubule with its forked end presents an appearance very like the letter $\mathrm{Y}$. The wall of the ureteric tubule is formed by simple, high columnar epithelium with large nuclei and deeply basophilic cytoplasm. The nuclei contain a rich chromatin network and one or more well-defined nucleoli. At the forking of the branches may be seen a large cell in mitosis.

The ureteric branches of the second order continue to grow, their cells proliferating by mitotic division. By the end of the second day in the allantois they in turn give rise to tertiary tubules. By further dichotomous division at the blind end of the newly formed tubules the ureteric tree grows and becomes more and more complex. Figure 4 shows the structure of the metanephros after two days' growth in the allantois. A secondary ureteric tubule $\left(\mathscr{Q}^{\prime}\right)$ is seen dividing into two tertiary tubules $\left(3^{\prime}\right)$. These have grown to a considerable length. At the blind end of the tertiary tubule ( $3^{\prime}$ ) a new subdivision is taking place, giving rise to tubules of the fourth order $\left(4^{\prime}\right)$. Subdivision of the primary ureteric branches goes on repeatedly in this manner, the branches so formed colresponding to the collecting tubules of the normal kidney. Each primary ureteric branch forms in this way a unit, the starting-point of a ureteric tree. The various lobules of the metanephric graft pictured in figure 7 correspond to these units, each lobule constituting a primary ureteric tree. As seen from the study of the growth of the 
ureteric epithelium in the allantois, the formation of the collecting tubules in the grafts does not differ from that usually described for their normal development within the organism.

On the other hand, the study of the ureteric epithelium in the allantois reveals in it a potency which is not exhibited under normal conditions, i.e., a phagocytic digestive capacity. Is might be expected, extirpation of the metanephric anlage from

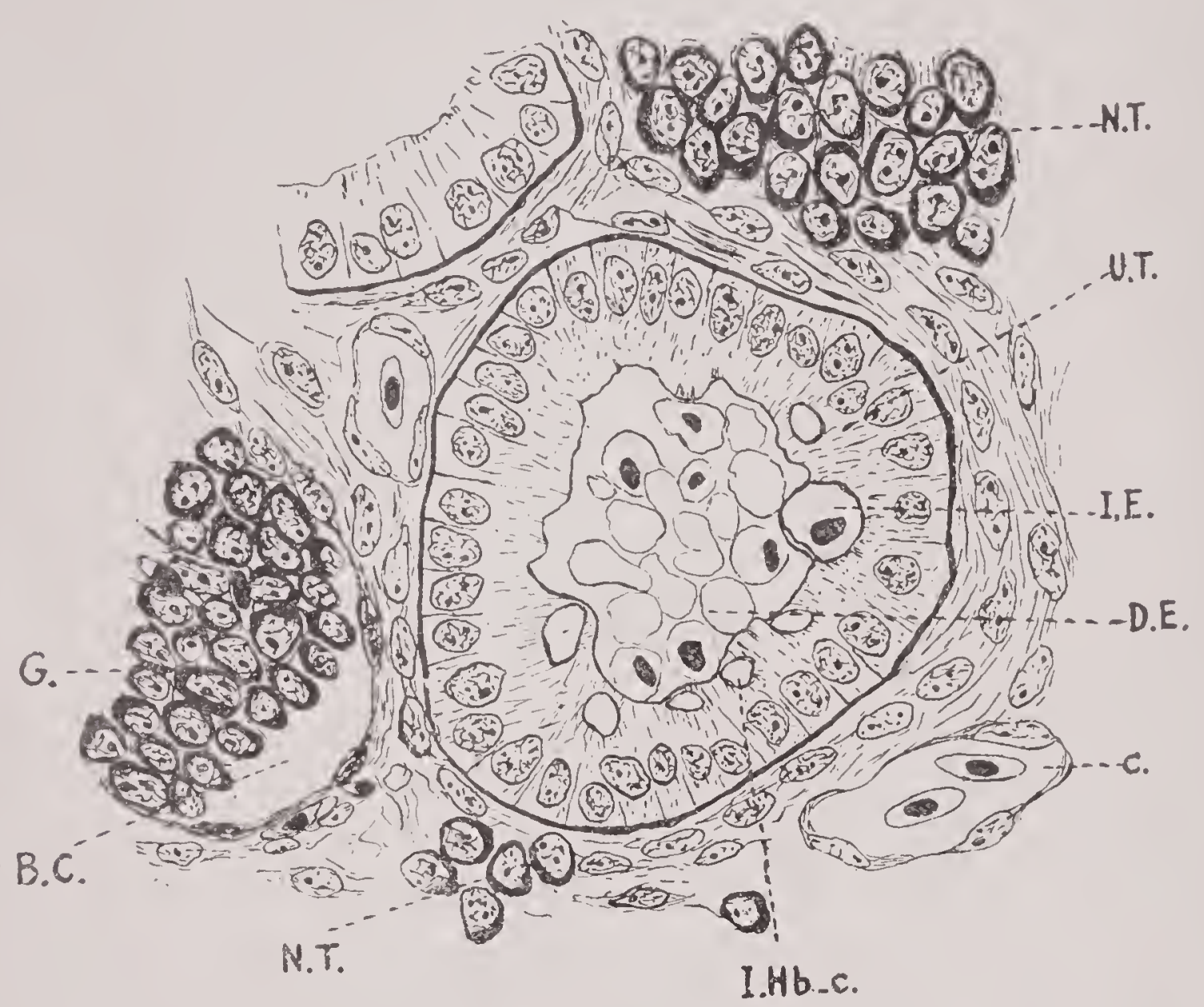

Text figure B Camera-lucida drawing to illustrate phagocytic activity of ureteric epithelium against degenerating red corpuscles. Metanephric graft of three days' growth. B.C., Bowman's capsule; c., capillary; D.E., degenerating erythrocytes; $G$, developing glomerulus; I.E., ingested erythrocyte; I. Hb-c., ingested hemoglobin-containing particle; N.T., nephrogenous tissue; U.T., large collecting tubules.

the body cavity of the embryo is usually accompanied by hemorrhage. It is not uncommon, therefore, in the grafts to find red blood corpuscles present in the lumen of the ureter bud. This new environment is apparently unfavorable for their maintenance and they gradually undergo degeneration. When degenerating erythrocytes are present within its lumen, the ureteric epithelium is seen to exhibit an intensive phagocytic activity. Text figure B 
shows a cross-section through a tubule filled with a mass of degenerating erythrocytes. Numerous epithelial cells lining the tubule are seen with cytoplasmic processes directed toward the mass of erythrocytes. In the lower part of the tubule may be seen actually ingested pieces of hemoglobin-containing cytoplasm (I.Hb.-c.). Above, the ureteric epithelium has ingested an erythrocyte, the nucleus of which has not yet disintegrated. Phagocytic activity by kidney cells of the frog has been described by Smallwood ('08) in a case of hemorrhagic kidney. He observed red blood corpuscles in the lumen of tubules and particles of hemoglobin-containing cytoplasm within the epithelium. Smallwood does not state in what kind of epithelial cells he found the ingested material, but judging from his figures it must have been the ureteric epithelium of large collecting tubules. The presence of degenerating corpuscles in the lumen of the ureteric tubules is frequent in the early stages of kidney growth in the allantois, but they are never found in grafts of six or more days' growth. One might conclude, therefore, that the process of digestion of the erythrocytes present in the tubules has been completed by this time.

2. Growth of the nephric epithetium. As stated above, the nephrogenous tissue at the time of grafting consists of a dense mass of mesenchymal cells clustering thickly about the branches of the ureteric diverticulum. This tissue likewise survives and grows in the allantois. It reaches a high degree of differentiation in the formation of typical nephric tubules.

In figure 3 the nephrogenous tissue appears as a continuous mantle of cells covering the forked terminations of the primary ureteric branch. The cells in immediate contact with the ureteric epithelium are thickly packed and arranged vertically with respect to the ureteric epithelium; the outer, more distal cells, are looser and are grouped concentrically about the more proximal cells. This arrangement of the nephrogenous tissue corresponds to that present in the anlage at the time of grafting (fig. 1).

As may be seen in figure 3 , several structural differences exist between the proximal and distal cells of the nenhrogenous tissue. 
The outer cells differ but slightly from the loose mesenchymal cells of the allantois. A number of them appear in the form of round, mobile cells. Their nuclei are large and vesicular with well-defined nucleoli. Their cytoplasm forms a narrow rim around the nucleus and appears to be more basophilic than that of the allantoic mesenchyme. The cell bodies are practically the same size as those of the surrounding mesenchyme. The cells in immediate proximity with the ureteric epithelium, on the other hand, have markedly hypertrophied-in some cases they appear two and three times the size of the more distal cells. The nuclei have become large and oval, containing prominent mucleoli; the cell bodies appear heavy and deeply basophilic. A difference in the metabolism of the two kinds of cells must have found its expression in this difference of structure.

With the growth of the ureteric tubules of the second order, the continuity of the nephrogenous mantle is broken and the nephrogenous tissue becomes split into separate masses. Part is carried forward on the blind terminations of the secondary tubules; part remains behind and condenses to form compressed spherical cell masses in the angles between the primary and secondary ureteric branches and between the two secondary branches. Figure 4 shows the nephrogenous tissue split into four separate cell masses. In this way the continuous mantle of nephrogenous tissue, such as that illustrated in figure 3 , becomes split into two caps of tissue covering the blind ends of the newly formed tubules and into a number of small islands, which remain in close relation with the primary ureteric branch. These islands of nephrogenous tissue are transformed into metanephric spheres similar to those of normal development. The close association between the metanephric spheres and the branches of the ureter bud is a constant one. In the grafts no metanephric sphere is found except in close relation with a ureteric tubule. The splitting up of the nephrogenous tissue proceeds hand in hand with the division and subdivision of the ureteric branches. The process is not dissimilar from that usually described for the typical development within the embryo. 
The uriniferous tubules develop out of the separate metanephric spheres. Figure 5 represents a section through a graft of the metanephric anlage after three days' growth in the allantois. Figure 6 represents another section through the same graft. Both photographs illustrate well the growth and differentiation of the nephric tubules in grafts at early stages. In figure 5 the nephrogenous tissue is seen split up into numerous small cell masses, the metanephric spheres. In some of these the process of differentiation is well started. Each cell mass is closely associated with a collecting tubule- a branch of the ureter bud.

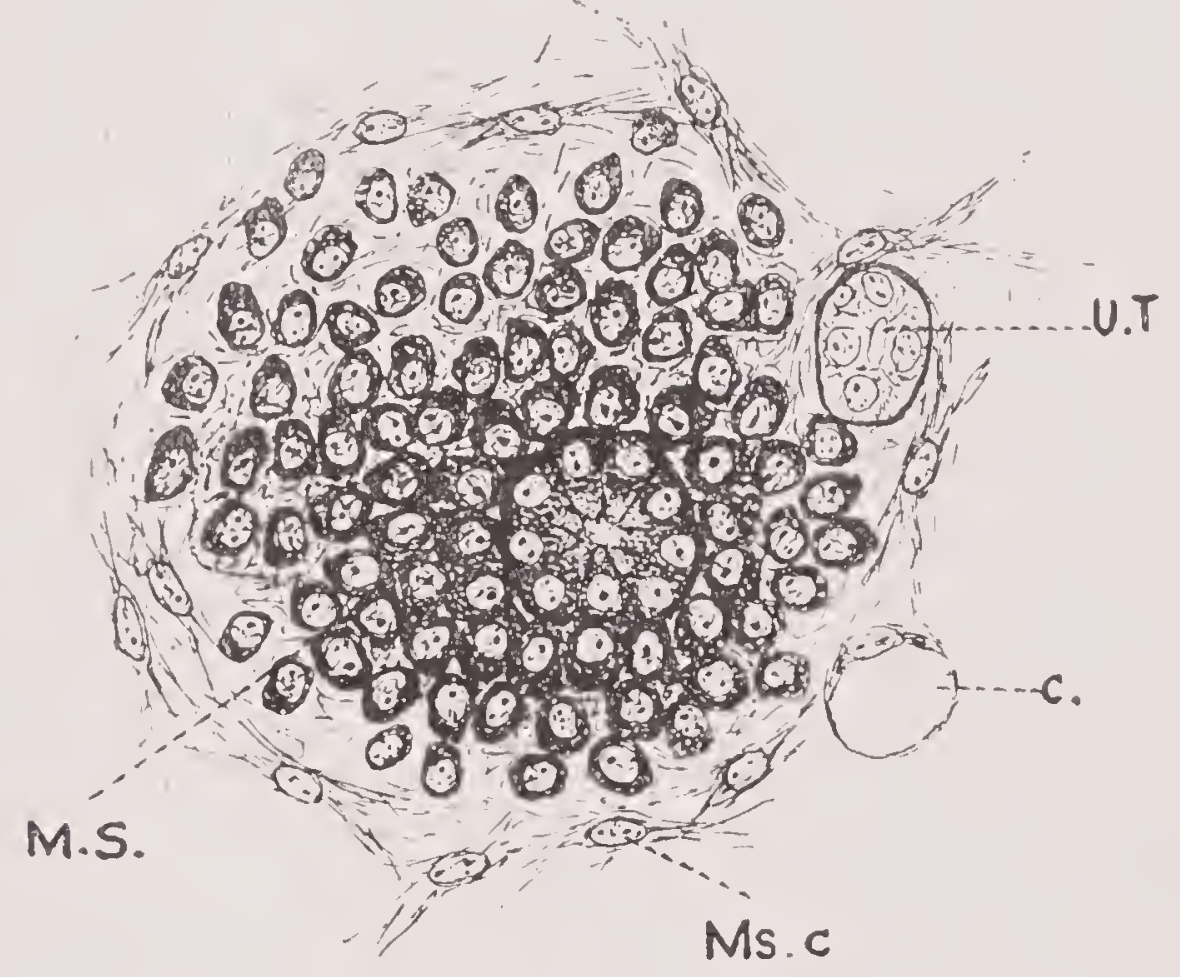

Text figure C Camera-lucida drawing to illustrate formation of lumen. Metanephric graft of four days' growth. $c$, capillary; M.S., metanephric sphere; Ms.c., mesenchymal cell; U.T., collecting tubule.

This relationship is not clear in figure 5 for every cell mass, but the study of the graft in serial sections readily proves that each cell mass without exception is in close association with a ureteric tubule. In these preparations ureteric tubules are easily distinguished from uriniferous tubules by their lighter stain.

At first the cells forming the metanephric spheres bear no definite relation to each other, but are heaped together in a haphazard fashion; for example, as in the cell mass (M.S.) in figure 4. During the second day's growth in the allantois these cells begin to group themselves radially about a point near the 
center of the metanephric sphere, the cells nearest the center acquiring a distinct epithelial arrangement. This stage is well illustrated in figure 5 (M.S.), and in figure 6 (M.S.). The central cells resemble the proximal, epithelially arranged cells of the nephrogenous mantle described in figure 3. They appear larger than the more peripheral cells of the cell mass with large oval nuclei. During this phase of development the cells are deeply basophilic. Soon, however, the central, radially arranged, epithelial-like cells undergo a change. At their pointed central ends the cytoplasm begins to take a faintly pinkish stain-a condition which might be considered a precursor of secretory activity. The central pointed ends are then flattened and pushed apart by the appearance of an acid-staining fluid at the point upon which the radially arranged cells had previously converged. Text figure $\mathrm{C}$ is a camera-lucida drawing illustrating this phenomenon. A distinct lumen is formed in later stages. 'It seems, therefore, that the formation of a lumen may be due to the products of secretory activity of the epithelial-like cells, which force the appearance of a space in the center of the metanephric sphere and subsequently its gradual widening. An analogous process was observed during the formation of the lumen in the normally developing metanephros of a nine-day chick embryo.

In this manner the metanephric sphere is converted into a thick-walled metanephric vesicle. A metanephric vesicle is found in figure $6(M . V$.$) . The vesicle grows, its lumen widens,$ and the whole structure appears to develop distally from the collecting tubules with which it is associated. The growth of the vesicle takes place not so much through mitotic division of its cells, as by addition of cells from the more peripheral parts of the sphere. Mitotic figures at this stage of development are not as numerous as one would expect. The outermost cells of the sphere, too, eventually seem to contribute to the formation of the nephric tubules. They gradually become exhausted, only a few cells remaining behind in the form of scattered mesenchymal cells situated among the developing renal tubules. The sharp distinction of the nephrogenous tissue into inner and outer zones, therefore, does not seem to be supported by these observations. 
The vesicles continue to grow and shortly acquire a triple bend forming the S-shaped structure so characteristic of the normally developing metanephros. Soon the blind end of the S-shaped tubule is seen in contact with the adiacent ureteric tubule. An opening is then established, the cells of the separating membrane being pushed aside and rearranged. In this way the nephric epithelium becomes continuous with the ureteric epithelium. From this time on growth of the tubule proceeds by mitotic division of the epithelial cells.

Figure 5 shows an $\mathrm{S}$-shaped tubule $(S)$. Its structure differs in no respect from the S-shaped tubule of the normal metanephros. The section following that from which figure 5 has been photographed shows that this tubule has already acquired an opening into the collecting tubule (U.T.). Just as in the normally developing uriniferous tubule, the S-shaped tubule of the grafts may be divided into three parts, an upper limb, middle piece, and lower limb. The distal part of the lower limb gives rise to Bowman's capsule. In the S-shaped tubule $(S)$ of figure 5 , the cells of the outer wall of the lower limb already appear flattened. The S-shaped tubule $(S)$ of figure 6 is in a still more advanced stage of differentiation. The distal end of the lower limb has grown around the structure in the form of a crescent, enclosing the upper limb within its ar'c. The cells of the outer or parietal layer are simple, flattened, and polygonal. The cells of the inner or visceral layer are likewise simple, but large and columnar and of a peculiar elongated pear-shape. The narrow interval between the two layers constitutes the uriniferous chamber. The same figure shows a Bowman's capsule (B.C.) in a still later stage of differentiation. The capsule has increased in size, its crescentic form tending to become more spherical. The urinary chamber appears greatly distended - a fact which might be taken as indirect evidence for the functional activity of the cells at this time.

The process of differentiation of the metanephric anlage in the allantois proceeds still further, leading to the appearance of typical glomeruli-structures which were not present at the time of grafting and which indeed do not appear in the normal 
metanephros until the ninth day of incubation. In the grafts the first signs of the glomeruli appear during the third day's growth. Tiny allantoic capillaries grow into the Bowman's capsules, forming the typical glomerular knots so characteristic of the normal development. Figure 6 shows well the ingrowth of the vessels into the Bowman's capsules of the graft. The space between the Bowman's capsule and the upper limb of the Sshaped tubule $(S)$ described above is occupied by a mass of mesenchymal cells. A capillary filled with erythrocytes is seen growing into this mass $(C)$. In the larger Bowman's capsule (B.C.) the vasculoconnective tissue appears greatly increased in amount. The capillary network is recognized by the presence of erythrocytes and a granular leucocyte. As a result of the process of differentiation described above, apparently normal Malpighian corpuscles are formed.

After several days' growth the metanephric anlage attains in the allantois a high degree of organization (figs. 2 and 7 ). Even under low power the tubules and Malpighian corpuscles are easily recognized. Huber ('17) has been able to identify the various segments of the uriniferous tubules of the adult fowl by isolating complete tubules through a process of maceration and teasing. It is possible to identify in sections from grafts of late stages segments of tubules corresponding to these described by Huber for the adult fowl. The secretory tubules are readily distinguishable from the collecting ones. The cytoplasm of the secreting epithelium is finely granular, and in eosin-azur preparations takes a pinkish stain. The cells are low columnar and somewhat pyramidal in shape. The segments of Henle's loop appear in grafts of seven or more days' growth, but never grow to their full extent. The collecting tubules, on the other hand, are characterized by clear, distinctly basophilic cytoplasm. Their cells are cuboidal, with round chromatic, centrally placed nuclei. The lumen of the collecting tubules seems wider than that of the secretory tubules. Text figures D and E are highpower camera-lucida drawings from grafts of six and eight days' growth and show various sections of the Malpighian bodies, the secretory and collecting tubules of the grafts, as they appear at these stages. 
3. Growth of the stroma. During the early stages of growth in the allantois, the loose mesenchyme of the anlage develops a high degree of vascularization. The development of the vessels was readily followed out. At the periphery of the anlage and later throughout its stroma spaces separating groups of individual cells are seen to appear. These spaces are apparently distended with fluid. The mesenchymal lining of the spaces, at first irregular in its outline, soon acquires the character of typical endo-

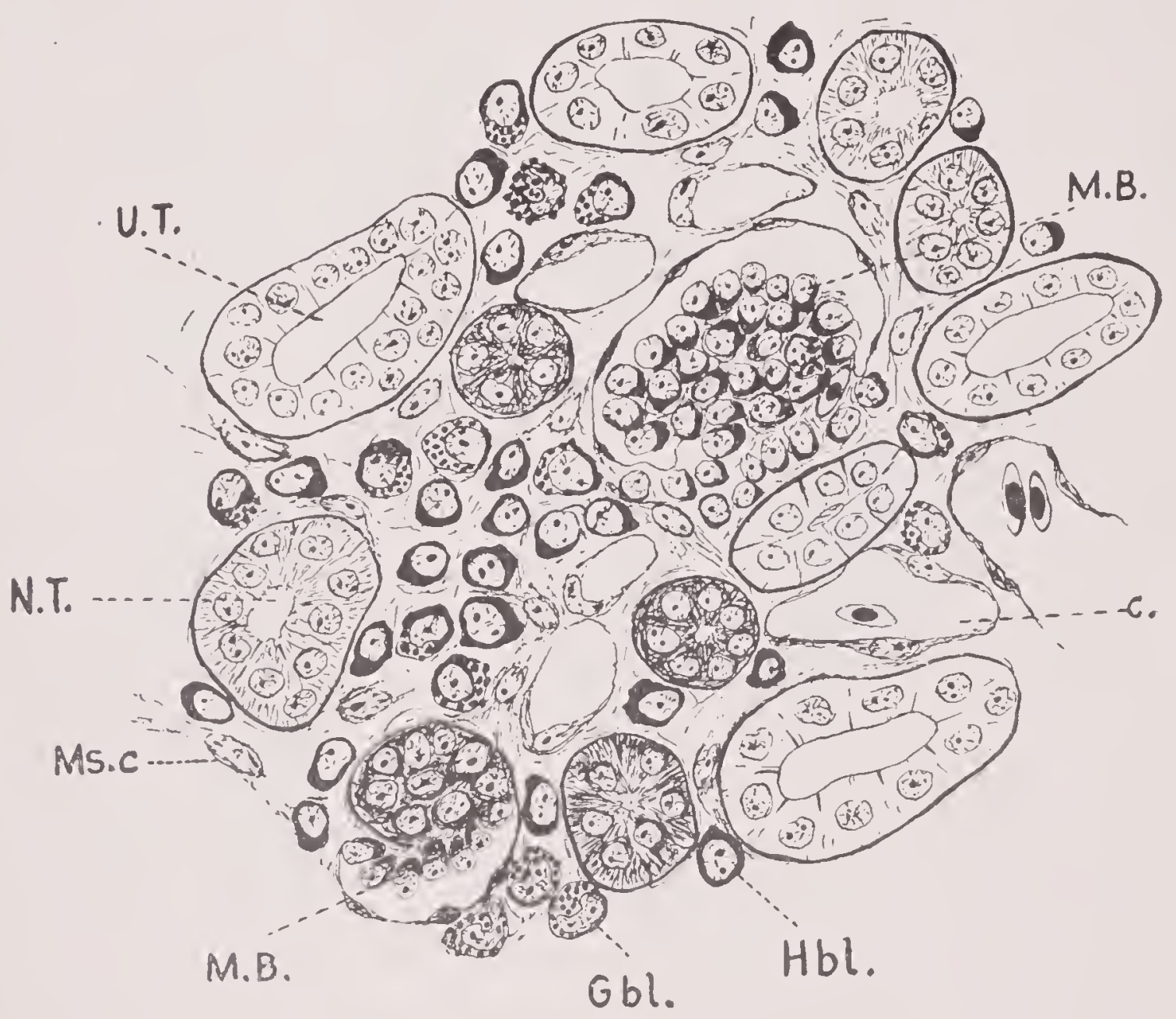

Text figure D Camera-lucida drawing to illustrate granulopoicsis and segments of urinary tubules. Metanephric graft of six days' growth. c., capillary; $G b l .$, granuloblast; Hbl., hemoblast; $M . B .$, Malpighian body; Ms.c., mesenchymal cell; N.T., secretory tubules; U.T., collecting tubule.

theilum. The spaces establish communications with one another, forming in this way a vascular net, which soon establishes connections with the allantoic vascular channels. Figure 7 illustrates the high degree of vascularization which develops in grafts of the metanephric anlage. Broad vascular channels encircle the organ and traverse the spaces separating its various lobes. Smaller vessels and capillaries are numerous between the lobules and among the nephric tubules. 
After the vascularization of the graft has become well developed, changes may be observed in the scanty mesenchymal cells of the stroma. In typical development these cells form the connective tissue of the kidney. In the grafts they take a new line of differentiation, developing into small, scattered foci of granuloblastic tissue.

The first signs of granuloblastic differentiation appear in grafts of six days' growth. This process is illustrated by text

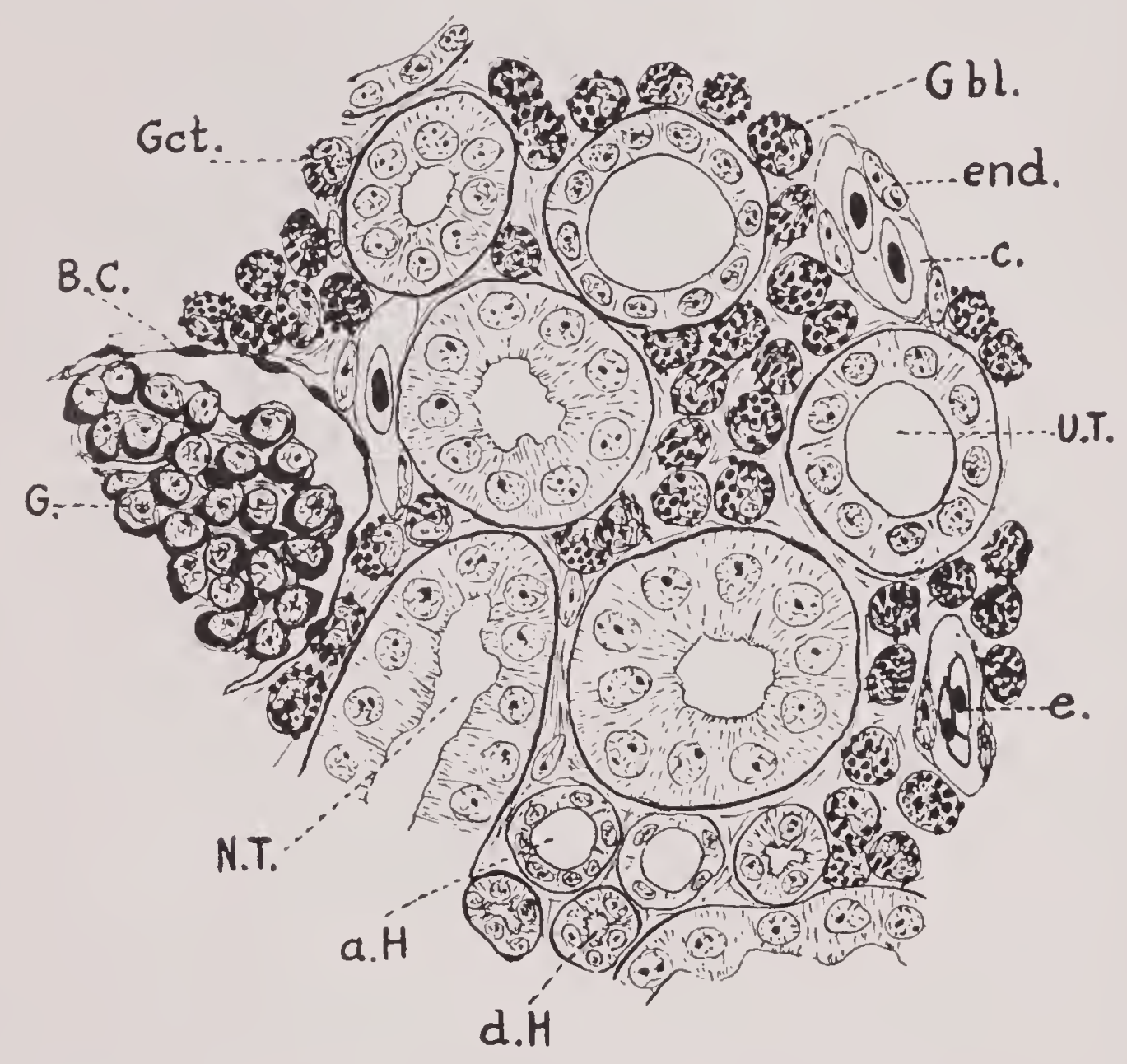

"Text figure E Camera-lucida drawing to illustrate granulopoiesis and various segments of urinary tubules. Metanephric graft of eight day's growth. a.H., ascending arm of Henle; B.C., Bowman's capsule; c., capillary; d.H., descending arm of Henle; end., endothelium; e., erythrocyte; $G$., glomerulus; Gbl., granuloblast; Gct., granulocyte; N.T., convoluted tubules; U.T., collecting tubule.

figure $\mathrm{D}$, in which can be seen an early stage in the development of a granulopoietic focus. Several mesenchymal cells have apparently lost their syncytial arrangement and appear as free, hypertrophied, deeply basophilic, amoeboid cells. They exhibit all the characteristics of typical hemoblasts. A few of these cells already contain acidophilic granules in their cytoplasm. In some the nucleus has become slightly polymorphic. 
These granuloblasts are undoubtedly of local origin, their gradual development from the mesenchyme being easily followed.

Text figure $\mathrm{E}$ illustrates the extent of the granuloblastic metaplasia which the stroma of the grafted anlage may attain. Heavy strands of granuloblasts fill in the spaces between the tubules. Granulopoiesis here appears in more advanced stages. Mature granulocytes with rod-shaped granules and lobulated nuclei have now developed. The intensive changes illustrated by this figure do not appear uniformly throughout the whole graft. In the central part of the lobules, where the tubules are closely packed together and the vascularization is scanty, only isolated granuloblasts can be found. A more or less intensive granulopoiesis, however, is regularly observed in regions where the stroma retains its loose texture and is well supplied by vascular channels.

\section{CONCLUSIONS AND DISCUSSION}

1. The metanephric anlage of the seven-day chick embryo, when isolated and grafted on the allantois of a chick embryo of the same age, not only survives, but grows into a large organ and attains a high degree of differentiation.

The ureter bud, which at the time of grafting has already begun to branch, forms typical collecting tubules. This process is exactly similar to that usually described for the formation of the collecting tubules of the metanephros developing within the embryo.

The nephrogenous tissue proper also continues its differentiation into the characteristic nephric vesicles. The nephrogenous cord, which at the time of grafting appeared in the form of a dense syncytium of apparently undifferentiated mesenchymal cells, proliferates and differentiates into a secretory epithelium. The formation of the lumen of the developing nephric vesicles appears to be the direct mechanical result of the secretory activity of the cells. The differentiation of the nephrogenous tissue leads to the appearance of typical glomeruli, structures which at the time of grafting were not present in the anlage. The growth and differentiation of the nephric tubules in the 
grafts may reach a high degree of organization. In older grafts convoluted tubules and segments of Henle can be identified. The process of growth and differentiation of the secretory part of the kidney on the allantois does not differ from that which normally takes place in the undisturbed kidney anlage.

The fact that the metanephric anlage of a seven-day chick embryo, when isolated from its normal relations within the organism and transplanted into the allantois, continues to differentiate into characteristic nephric tubules seems to indicate that at this time the young anlage has already become specifically organized. Contrary to the results obtained by Champy, the parts of the anlage already differentiated (ureteric epithelium, epithelially arranged cells of the nephrogenous tissue) do not undergo a series of reversible changes, but show a marked capacity to retain their epithelial arrangement and to differentiate still further. Moreover, the apparently undifferentiated part of the anlage, which at the time of grafting appeared in the form of a dense syncytium of mesenchymal cells, showed the ability to acquire an epithelial arrangement and to form typical nephric tubules. The process of differentiation proceeds to such an extent that even the allantoic capillaries are induced to form. typical glomerular knots within the concavities of the Bowman's capsules. The allantois seems to be as favorable a medium for the growth and differentiation of the metanephric anlage at this stage as its normal environment within the organism. The grafted anlage may attain the same general form, size, and structure as that of the normal kidney of corresponding age.

Not only does the transplanted metanephros acquire the structure of the normally developing kidney, it also, as far as histological evidence can determine, develops physiological activity. This development of both structure and function in the grafted anlage takes place despite the fact that it can be of no possible use to the general organism, since there is no outlet in the transplanted metanephros whereby the graft can get rid of the products of its secretory activity. Champy has ascribed the process of dedifferentiation of the metanephros in his cultures to 
lack of functional stimulus. But, despite lack of functional stimulus, cultures of the metanephros in the allantois attain a high degree of differentiation. It is possible that the different results obtained by Champy and myself may be due to a difference in the milieu in which the cultures were planted. A tissue possessing the potency will differentiate into nephric tubules, provided the conditions for its grow th and differentiation are favorable. Under other conditions, this process may not take place, and even a tissue already specialized may lose its specific structures, as Champy seems to have shown.

2. A digestive power is revealed by the ureteric epithelium which may be seen to ingest and digest red blood corpuscles.

Unimportant as it may seem, the observation on the phagocytic and digestive activity displayed by the epithelial cells of the collecting tubules may prove of interest in view of the vast rôle of digestive activity recently attributed to the general mesenchyme (Danchakoff, '21). This power of digestion may sometime in the future be recognized as an active and simple agent in the so-called defenses of the organism. In this particular case a specialized mesodermal cell, the epithelial cell of the collecting tubules, exercises phagocytic and digestive activity. Other apparently specialized cells in the organism, for example, endothelial and mesothelial cells, although in the form of epithelial membranes, retain and exercise to a considerable extent the fundamental biological property of digestion.

3. The stroma of the grafted anlage develops along lines different from that characteristic of its normal development. Normally this tissue gives rise to sparse connective-tissue cells; in the grafts it is transformed into large, scattered foci of granuloblastic tissue. The granuloblastic activity displayed by the loose mesenchyme of the metanephric anlage in these grafts affords additional evidence for the equivalence of the mesenchyme and for its polyvalency in the different parts of the organism. In this instance the granuloblastic differentiation of the mesenchyme is the more interesting since, of all regions of the embryo's body, the mesenchyme of the metanephros has shown itself the least responsive to this change after grafts of adult 
splenic tissue. The granuloblastic differentiation of mesenchymal cells is once more shown to be dependent upon environmental conditions.

\section{LITERATURE CITED}

Carrel, A., And Burrows, M. 1911 Cultivation of tissues in vitro. Journ. Exper. Med., vol. 13, pp. 387-396.

Champy, C. 1913 La différenciation des tissus culturés en dehors de l'organisme. Bibl. Anat., T. 23, p. 184.

1913 Sur les phénomènes cytologiques qui s'observent dans les tissus culturés en dehors de l'organisme. Tissus epithéliaux et glandulaires. Compt. rend. soc. biol. Paris, T. 72, p. 987.

1914 Quelques resultats de la méthode des cultures de tissus, le rein. Arch. de Zool. Exper. et Gen., T. 54, pp. 307-386.

Danchakoff, Vera 1916 The wandering cells in the loose connective tissue of the bird and their origin. Anat. Rec., vol. 10, pp.483-492.

1916 The differentiation of cells as a criterion for cell differentiation considered in relation to the small cortical cells of the thymus. Journ. Exper. Med., vol. 24, pp. 87-105.

1916 Equivalence of different haematopoietic anlages (by method of stimulation of their stem cells). I. Spleen. Am. Jour. Anat., vol. 20, pp. 255-308.

1918 Equivalence of different haematopoietic anlages (by method of stimulation of their stem cells). II. Grafts of adult spleen on the allantois and response of the allantoic tissues. Am. Jour. Anat., vol. 24 , pp. $127-173$.

1920 Immunity and the power of digestion. Bull. Marine Biol. Lab., vol. 38, p. 202.

1920 Myeloid metaplasia of the embryonic mesenchyme in relation to potentialities and differential factors. Contrib. no. 49, Carnegie Institution of Washington.

1921 Digestive activity of mesenchyme. A. The Ehrlich sarcoma cells as object. Am. Jour. Anat., vol. 29, pp. 431-489.

Felix, N., ANd Buehler, A. 1906 Die Entwickelung der Harn und Geschlechtsorgane. Handbuch der Vergleichender u. experimentaler Entwickelungslehre der Wirbeltiere. Herausgegeben von Oskar Hertwig, Bd. 3, S. 81.

HARRISON, Ross G. 1904 An experimental study of the relation of the nervous system to the developing musculature in the embryo of the frog. Am. Jour. Anat., vol. 3.

Huber, G. CArL 1917 On the morphology of the renal tubules of vertebrates. Anat. Rec., vol. 13, pp. 305-339.

Huntington, George S. 1914 The development of the mammalian jugular lymph sac of the tributary primitive ulnar lymphatic and of the thoracic ducts from the viewpoint of recent investigations of the vertebrate lymphatic ontogeny, together with a consideration of the genetic relations of the lymphatic and haemal vascular channels in the embryos of amniotes. Am. Jour. Anat., vol. 16, pp. 259-316. 
JANosik, J. 1907 Ueber die Entwickelung der Nachniere bei den Amnioten. Arch. f. Mikr. Anat. u. Entw., Bd. 70, S. 23-82.

Lillie, Frank R. 1908 The development of the chick. Henry Holt \& Co.

Maximov, A. 1907 Experimentelle Untersuchungen zur post-foetalen Histogenese des myeloiden Gewebes. Zieg. Beitr., Bd. 41, S. 112-166.

Poscharisskx, J. F. 1905 Ueber heteroplastiche INnoch enbildung. Zieg. Beitr., Bd. 38, S. 135-176.

Sacerdotti, C., And Frattin, G. 1902 Ueber die heteroplastische Kinochenbildung. Virch. Arch., Bd. 168, S. 431-443.

Simallwood, N. M. 1908 The kidney cells of the frog in phagocytic rôle. Anat. Anz., Bd. 32, S. 201-205.

Uhlenhuth, E. 1912 Die transplantation des Amphibiensauges. Arch.f, Entw. des. Org., Bd. 33, S. 723-747.

1915 The form of the epithelial cells in cultures of the frog skin and its relation to the consistency of the medium. Jour. Exper. Med., vol. 22, pp. $76-104$. 
PLATE 1

EXPLANATION OF FIGURES

1 Photograph of metanephric anlage of seven-day chick embryo to illustrate stage of differentiation at time of grafting. The ureter bud has given off primary branches, which in turn have begun dichotomous division to form secondary branches. The ureteric branches are capped with a dense mantle of nephrogenous tissue.

2 Photograph from section of graft of metanephric anlage after seven days' growth in the allantois.

3 Photograph from a graft of the metanephric anlage after twenty-four hours' growth in the allantois. A primary ureteric tubule has begun dichotomous division forming ureteric tubules of the second order. The ureteric epithelium is covered with a continuous mantle of nephrogenous tissue.

4 Photograph from a graft of the metanephric anlage after two days' growth in the allantois. To illustrate branching of ureteric tubules and splitting of nephrogenous tissue. M.S., metanephric sphere; $2^{\prime}$, ureteric tubule of second order; $3^{\prime}$, ureteric tubule of third order"; 4', early stage in dichotomous division to form ureteric tubule of fourth order. 
RUTH RAND ATTERBURY
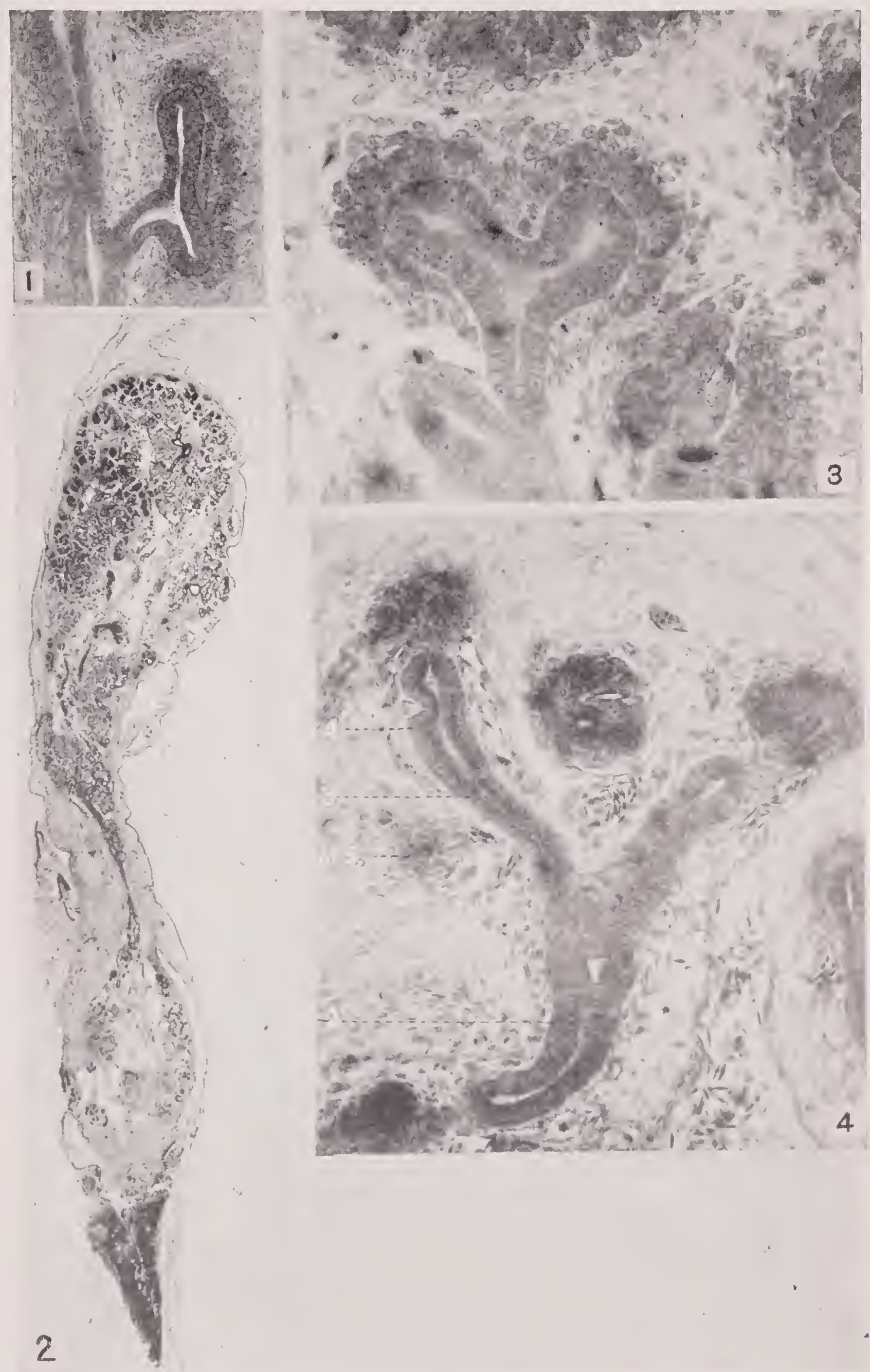
PLATE 2

EXPLANATION OF FIGURES

5 Photograph from a graft of the metanephric anlage after three days' growth in the allantois. To illustrate early stages in development of nephric tubules. II.S., metanephric sphere with central cells radially arranged; $S$, S-shaped tubule; U.T., ureteric tubules.

6 Photograph from a graft of the metanephric anlage after three days' growth in the allantois. To illustrate development of Malpighian corpuscles. B.C., Bowman's chamber; $c$., capillary; $G$., developing glomerulus; M.S., metanephric sphere; M.V., metanephric vesicle; $S$. , S-shaped tubule with distal end differentiating to form Bowman's capsule; $U . T$., collecting tubule. 

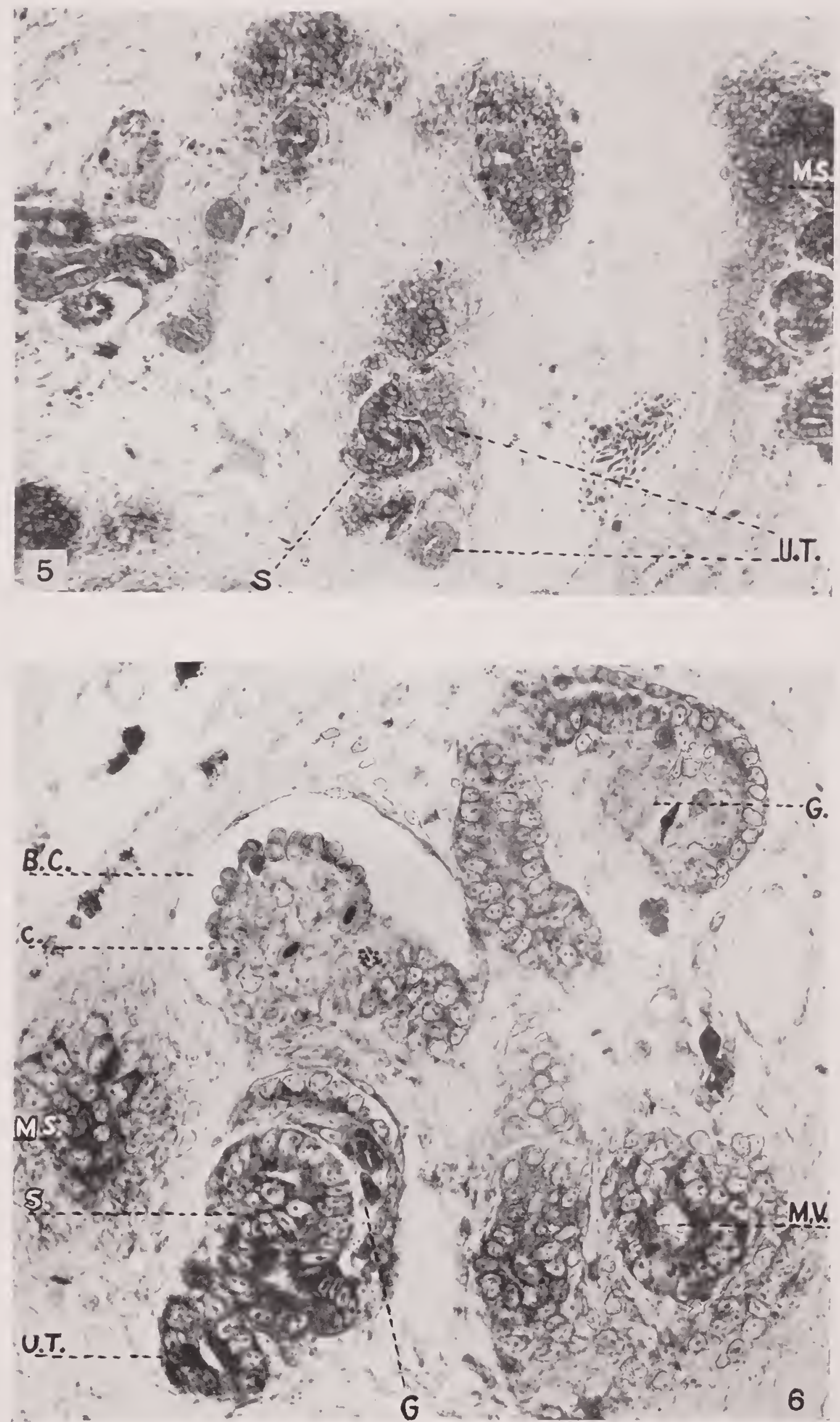
PLATE 3

EXPLANATION OF FIGURE

7 Photograph from a graft of the metanephric anlage isolated from a sevenday chick embryo and grown ten days in the allantois. To illustrate extent of growth and differentiation which metanephric anlage may attain. 


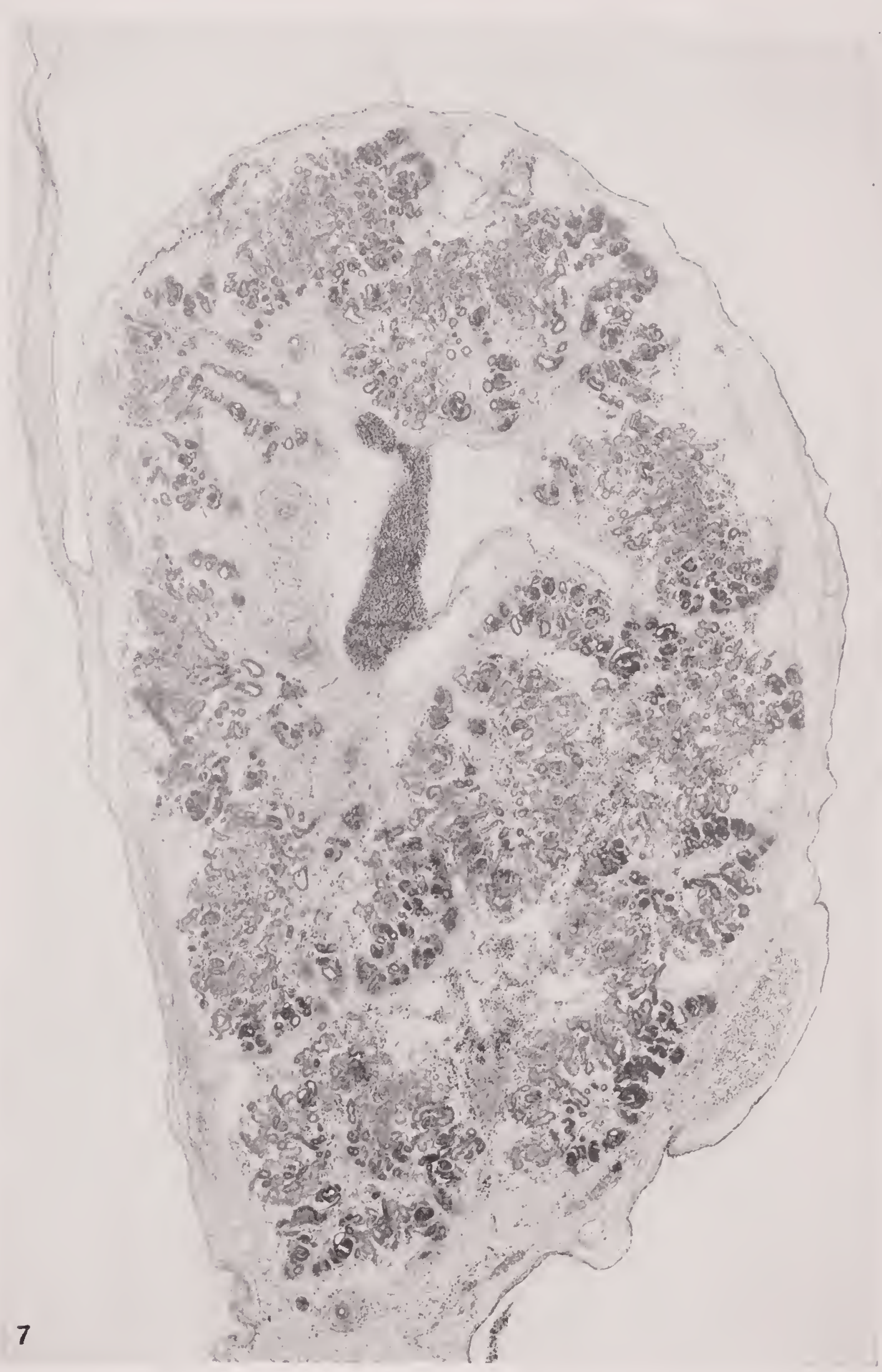





\section{VITA}

1. Date of Birth: May 23, 1895.

2. Place of Birth: New York City.

3. Educational Institutions Attended:

Wellesley College, Wellesley, Massachusetts, 1912-1916.

Cornell University, Ithaca, New York, 1916-1918.

Cornell Medical School, New York City, 1918-1919.

College of Physicians and Surgeons, Columbia University, New York City, 1919-1922.

4. Degrees:

Bachelor of Arts, Wellesley College, 1916.

Master of Arts, Cornell University, 1917.

5. Honor's :

Durant Scholar (Junior and Senior), Wellesley College, 1915-1916.

Sigma XI, Cornell University, 1917.

6. Publications:

(1) On the Relation of the Head Chorda to the Pharyngeal Fpithelium in the Pig Embryo. A Contribution to the Development of the Bursa Pharyngea and the Tonsilla Pharyngea.

Anat. Record, Vol. 13, pp. 465-491, 1917.

(2) Bursa and Tonsilla Pharyngea. A Note on the Relations in the Embryo Calf.

Anat. Record, Vol. 16, pp. 251-264, 1919.

(3) Potentialities of Different Parts in the Kidney Anlage. Abstr. Proc. Anat. Record, Vol. 18, p. 219, 1920. 



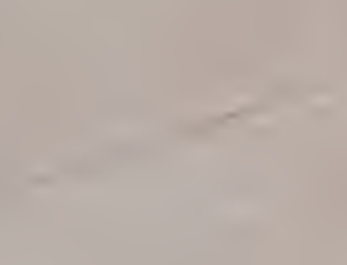


